\title{
Práticas que integram a saúde mental à saúde pública: o apoio matricial e a interconsulta
}

\author{
Practices that integrate mental health with public health: \\ matricial support and interconsultation
}

${ }^{1}$ Prefeitura Municipal de Porto Alegre. Rua Moab Caldas 400, Santa Teresa. 90880-310 Porto Alegre RS. rosilelaine@gmail.com

\begin{abstract}
This article is an offshoot of my doctoral thesis defended at the Federal University of Rio Grande do Sul. It seeks to approach the historical dissociation between mental health and broader public health as well as practices that work towards the integration of the two. It examines the scientific background that fosters this dissociation and also national and international health-related documents that stress the need for integration. Based on Rose, I analyzed the documents and interviews with health professionals on the practices of Matricial Support and Interconsultation formulated by the Ministry of Health and by the Porto Alegrel Rio Grande do Sul Municipal Health Department, which seek to relate mental health with Primary Healthcare. These documents and health practices propose new subjectivations to the professionals. They emphasize the interdisciplinarity and the non-hierarchization of services and knowledge, and are in line with the form of contemporary social organization, which suggests taking horizontal and democratic decisions, rather than decisions imposed by a vertical authority typical of the patriarchal and biomedical model. Key words Mental health, Public health, Primary healthcare, Matricial support, Interconsultation
\end{abstract}

Resumo Este artigo é um desdobramento da Tese de Doutorado defendida na Universidade Federal do Rio Grande do Sul. Tem como objetivo abordar a histórica dissociação entre a saúde mental e a saúde pública mais ampla bem como as práticas que propõem sua integração, examinando o contexto científico que produz esta dissociação bem como os documentos nacionais e internacionais na saúde que referem à necessidade de integração. Foram analisados a partir de Rose os documentos e entrevistas com profissionais da saúde sobre as práticas de Apoio Matricial e Interconsulta formuladas pelo Ministério da Saúde e pela Secretaria Municipal de Saúde de Porto Alegre (RS), que pretendem relacionar a saúde mental com a Atenção Primária à Saúde. Estes documentos e práticas da saúde propõem aos profissionais novas subjetivações. Enfatizam a interdisciplinaridade e a não hierarquização de serviços e saberes, e estão em consonância com a forma de organização social contemporânea, que propõe que se assumam decisões horizontais e democráticas, em vez de impostas por uma autoridade vertical típica dos modelos patriarcal e biomédico.

Palavras-chave Saúde mental, Saúde pública, Atenção primária à saúde, Apoio matricial, Interconsulta 


\section{Saúde mental e saúde:} uma histórica dissociação

Este artigo é um desdobramento da Tese de Doutorado intitulada "Práticas pedagógicas na saúde: o apoio matricial e a interconsulta integrando a saúde mental à saúde pública" ${ }^{1}$, defendida no Programa de Pós Graduação em Educação da Universidade Federal do Rio Grande do Sul. A pesquisa se realizou a partir de uma abordagem construcionista cultural que, segundo $\mathrm{Hall}^{2}$, considera que o significado é construído na e através da linguagem, que as "coisas" não têm um significado inerente, nem os significados são apenas individuais, entendendo ser o significado produzido pelo trabalho da representação e das práticas de significação.

Embora a saúde mental faça parte da saúde mais ampla, é comum na rede básica os profissionais generalistas atenderem a um leque diversificado de situações como desnutrição infantil, hipertensão em adultos, diabetes, entre outros, mas não incluírem a saúde mental ou as manifestações da subjetividade como parte deste leque. Acreditam ser esta da alçada do serviço especializado, sem que muitas vezes considerem a possibilidade de alguma assistência ser procedida no âmbito da Atenção Primária à Saúde (APS). Também é observável uma falta de aproximação entre ações voltadas a diabetes, a saúde da mulher, da criança, do adolescente, do idoso, por exemplo, e a saúde mental, tanto no planejamento dos programas e políticas quanto na execução da assistência. As diferentes políticas colocadas em ação, como por exemplo, a Política de Atenção Integral à Saúde da Mulher, a Política de Saúde do Idoso, a Política de Saúde Mental, comumente ou são pouco articuladas entre si ou não o são. Assim, discussões referentes à saúde mental, ao sofrimento psíquico ou à subjetividade, que a princípio seriam transversais a qualquer outro programa e política pública de saúde, comumente não perpassam esses programas. Dessa forma, as ações e o cuidado em saúde se processam, com frequência, de forma compartimentada, fracionando o atendimento e o sujeito, que também é atendido de forma fragmentada: cada "fragmento" é remetido para um serviço diferente, ou para um programa específico, ou para um profissional específico, sem que haja, muitas vezes, uma articulação entre eles, gerando-se, assim, como salientou Ceccim³ ${ }^{3}$, uma parcelarização técnicoburocrática do trabalho.

Esse é o aspecto que justifica meu interesse pelas práticas da Interconsulta e do Apoio Matri- cial na área de saúde mental, pois estas objetivam articular áreas, saberes, serviços, a saúde mental e a saúde no sentido geral. Em termos gerais, estas práticas consistem em encontros interdisciplinares entre profissionais que trabalham nos serviços de saúde mental (psicólogo, psiquiatra, terapeuta ocupacional e outros) e profissionais que trabalham nos postos de saúde da rede básica (médico, enfermeiro, agente comunitário e outros) para que os primeiros auxiliem os segundos, principalmente a respeito da avaliação e do atendimento de casos que precisam de atenção em saúde mental, com o intuito de que possam acolher e acompanhar alguns casos que talvez não necessitem de atenção especializada.

A percepção desta dissociação entre saúde mental e saúde no sentido mais amplo, verificada nas práticas dos serviços, também se encontra referida em vários documentos nacionais e internacionais na saúde, que abordam também a necessidade de integrá-las, conforme será citado. O documento internacional elaborado pela Organização Mundial da Saúde, intitulado "Relatório sobre a saúde no mundo 2001: Saúde mental: nova concepção, nova esperança"4, considera ser a saúde mental comumente ignorada e negligenciada, diferente do que sucede com a saúde física, ressaltando ser a maioria das doenças mentais e físicas influenciada por uma combinação de fatores biológicos, psicológicos e sociais. Este documento indica que muitos países não possuem orçamentos específicos para a saúde mental, e boa parte daqueles que a incluem entre seus gastos consigna menos de $1 \%$ do orçamento da saúde pública para a saúde mental. A nova concepção a que alude o título do documento, é a de que saúde mental e saúde física são inseparáveis, que uma influencia a outra, e que a saúde mental, os sentimentos e os pensamentos, são tão importantes quanto a saúde física. E os estados afetivos angustiados e deprimidos desencadeiam mudanças no funcionamento endócrino e imunitário e criam suscetibilidades a doenças físicas, estando entre essas os distúrbios cardíacos. E comumente os profissionais da atenção primária não reconhecem a angústia emocional, propondo o treinamento destes profissionais para detecção e tratamento de transtornos mentais. Outro documento mais recente, elaborado pela Organização Mundial da Saúde ${ }^{5}$ juntamente com a Associação Mundial de Médicos de Família (WONCA), indicou entre outras, as seguintes razões para a integração da saúde mental na APS: as altas prevalências de transtornos mentais e o baixo número de pacientes que recebem 
tratamento em todos os países; o aumento do acesso aos cuidados em saúde mental, quando realizados na APS; a maior qualificação das ações e dos serviços desenvolvidos na APS minimiza o estigma e a discriminação; é mais barato para pacientes, comunidades e governos o tratamento em saúde mental na APS que em hospitais psiquiátricos; e os bons resultados obtidos relativamente à integralidade da saúde de sujeitos com sofrimento psíquico.

Outro documento internacional é a Declaração de Caracas ${ }^{6}$, que defende desde a década de 1990, a atenção psiquiátrica na Atenção Primária à Saúde e na comunidade, propondo não centrar a assistência à saúde mental nas internações hospitalares.

Em nível nacional, o documento do Ministério da Saúde sobre o Núcleo de Apoio à Saúde da Família ${ }^{7}$ também enfatiza a integração da atenção à saúde mental na APS. Refere estudos realizados na década de 1980, que demonstraram que entre os pacientes que procuram o Programa Saúde da Família 33\% a 56\% apresentava "transtornos mentais comuns". A respeito destes o documento cita o estudo da OMS, divulgado em 2001, que encontrou com maior frequência na APS a coexistência de depressão e ansiedade, além de sintomas físicos que não recebem explicação médica. Este documento utiliza tais indicações para justificar a necessidade de qualificar a APS e aponta a melhoria da efetividade na atuação das equipes de Saúde da Família possibilitada pelo Apoio Matricial em saúde mental.

Como vimos, há ainda hoje em documentos recentes uma ênfase na necessidade de integração entre saúde mental e saúde física, e a insistência nessa temática, em nível internacional e nacional, é um indicativo de que se considera que ainda não foi alcançada plenamente.

Também autores como Lancetti e Amarante ${ }^{8}$ consideram fundamental o papel da rede básica na Reforma Psiquiátrica, pois para eles a saúde mental é o eixo da Estratégia da Saúde Família (ESF) e esta é um programa de saúde mental, pois trabalha próximo à comunidade, todos os profissionais conhecem os pacientes pelo nome bem como suas histórias. Consideram que a Saúde da Família tem poder de inserção dos indivíduos ao seu território mais que os CAPS, pois a saúde mental compete a todos profissionais de saúde.

\section{Contingências de produção da dissociação e da integração entre saúde mental e saúde física}

Tal como propõe Foucault ${ }^{9}$, não interessa buscar a origem dos acontecimentos ou uma identidade primeira, na qual estivesse assentada a verdade, entendida como algo anterior a tudo que é externo, acidental e sucessivo, mas de considerar sua proveniência e emergência. Nessa mesma direção, autores que se utilizam de Foucault, como Kendall e Wickham ${ }^{10}$, ressaltam que se deve procurar pelas contingências, e não pelas causas, pois um evento histórico não deve ser visto como necessário, mas como decorrente de uma série de relações complexas procedidas entre outros eventos. Dessa forma, busquei indagar a emergência ou o contexto social e na saúde a partir do qual se propõem as práticas como o Apoio Matricial e a Interconsulta.

O surgimento da ciência moderna foi o momento onde se deu o processo de multiplicação e criação de diferentes disciplinas e saberes, das fronteiras entre eles e das tentativas de interrelacioná-los, bem como surgiram as dicotomias entre mente/corpo e sujeito/objeto, segundo Luz $^{11}$. As disciplinas científicas que emergiram nesta época e posteriormente, tais como a Física, a Química, a Fisiologia e a Medicina, reproduziram nas suas teorias estas dualidades e dicotomias, apesar de periodicamente também reduzirem um polo da dicotomia a outro, como a autora também salientou. Segundo Capra ${ }^{12}$ e Minayo ${ }^{13}$, estas dicotomias do modelo cartesiano da ciência deram origem na saúde à separação entre os profissionais que se ocupam do corpo e os profissionais que se ocupam da mente, dividindo a prática da assistência em dois campos distintos com pouca comunicação: os médicos ocupam-se do tratamento do corpo, os psiquiatras e psicólogos da cura da mente, hiato que impede a compreensão da relação entre aspectos emocionais e físicos no curso das doenças. Bem como corroborou a separação entre a doença ou o corpo (o objeto) e as representações e as significações do sujeito sobre elas (o sujeito).

Também faz parte deste modelo científico positivista a valorização do discurso da Razão, dos aspectos quantitativos em detrimento dos qualitativos, da objetividade em detrimento da subjetividade. Um representante importante do positivismo na saúde é o modelo biomédico que valoriza a especialização, o trabalho isolado, a objetividade em detrimento dos aspectos psíquicos ou subjetivos. 
A forma discursiva e a prática biomédica preponderantes na saúde, segundo Ceccim e Capazolo ${ }^{14}$, enfocam principalmente os determinantes biológicos do adoecimento, sendo essa uma "racionalidade que busca a verdade das doenças na alteração anatomopatológica”. Nesse modelo o hospital e as emergências são considerados como centrais e como o topo da hierarquia da rede assistencial e a rede de serviços como um todo é pouco articulada e valorizada, sendo um sistema burocratizado e verticalizado. Ocorre, também, uma organização fragmentária do trabalho, tanto na assistência quanto nos processos de trabalho, gerando alienação no cuidado e na sua finalidade. E um padrão tecnicista e rotinizado de atenção, que considera pouco as singularidades dos casos e medicaliza em alto nível, levando em conta, principalmente, o saber epidemiológico, deixando como secundário o atendimento individual e o saber da clínica.

Em contraposição ao modelo hospitalocêntrico encontra-se o conceito ampliado de saúde que integra a saúde mental e não foca apenas no aspecto biológico das doenças, mas define a saúde como um bem-estar físico, mental e social - e está presente em vários documentos internacionais e nacionais como a Constituição da $\mathrm{OMS}^{15}$ de 1948 e também o capítulo sobre o SUS da Constituição Federal de $1988^{16}$. A Reforma Psiquiátrica que hoje faz parte da Política de Saúde Mental ${ }^{17}$ do Ministério da Saúde propõe a inserção social na comunidade do doente mental e também faz parte deste contexto de produção desta ideia de integrar saúde mental e saúde física. E a ênfase dada nas últimas décadas na Atenção Primária à Saúde - desde a Declaração de Alma-Atá de $1978^{18}$-, ao invés da valorização apenas dos hospitais enquanto centro da assistência na saúde, também forma o contexto onde se promovem as práticas de Apoio Matricial e Interconsulta. Esses são hoje os discursos de verdade colocados na saúde e que informam as práticas abordadas.

\section{Aportes metodológicos}

O Apoio Matricial foi teorizado por Campos e Domitti ${ }^{19}$ e propõe um arranjo organizacional que estabeleça uma relação dialógica horizontal entre profissionais do serviço de referência (a rede básica, por exemplo) e do serviço especializado, ampliando a clínica. A Interconsulta teorizada por
Botega ${ }^{20}$ propõe assessorar em saúde mental os profissionais e as equipes não especializadas, entre outras atividades. Ambas buscam integrar a saúde mental à saúde mais ampla e são propostas dos órgãos oficiais a nível federal e municipal.

A metodologia utilizada foi a pesquisa qualitativa, a entrevista semiestruturada e a análise baseada em Rose ${ }^{21}$. Segundo esta autora, um primeiro tipo de análise do discurso foucaultiana examina como as visões ou relatos são construídos como reais, verídicos ou naturais, conformando regimes de verdade. Enfoca estratégias de persuasão ou os modos como determinado discurso consegue persuadir e produzir efeitos de verdade, bem como posições de sujeito. Esta primeira forma de análise aborda a produção social e os efeitos dos discursos. Um segundo tipo de abordagem analítica foucaultiana, examina a maneira como os discursos institucionais são materializados na própria arquitetura e nas posições de sujeito. Ou seja, articula-se poder/saber e a produção de posições de sujeito relacionadas aos mesmos. Como o autor ${ }^{21}$ refere, estas duas formas de análise podem acontecer de maneira bastante relacionada.

Foi realizada a análise de dois documentos do Ministério da Saúde sobre Apoio Matricial ${ }^{22,23}$ e um da Secretaria Municipal da Saúde de Porto Alegre/RS sobre Interconsulta ${ }^{24}$, e de entrevistas com doze profissionais da Secretaria Municipal da Saúde (SMS), sete profissionais de serviços de saúde mental (psicólogo, terapeuta ocupacional, psiquiatra, assistente social) e cinco médicos de serviços da rede básica (Estratégia de Saúde da Família e Unidade de Saúde). Este tipo de análise não busca indicar qual a melhor prática ou a mais produtiva - se a Interconsulta ou o Apoio Matricial - mas relatar como estas são significadas pelos documentos e pelos profissionais. A escolha destes documentos para análise se deveu ao fato de serem as referências oficiais que embasam estas práticas realizadas pelos trabalhadores da SMS de Porto Alegre/RS e que propõe articular os serviços de saúde mental e a rede básica. A escolha dos sujeitos se direcionou aos que participam destas práticas em diferentes serviços da cidade, sem pretender abranger todos. A entrevista indagou como realizam e o que os profissionais pensam delas.

Esta pesquisa foi aprovada pelo Comitê de Ética da Secretaria Municipal de Saúde de Porto Alegre/RS e não recebeu financiamento para a sua realização. 


\section{Novas subjetivações na saúde}

Os documentos do Ministério da Saúde analisados sobre Apoio Matricial foram:

1) "Saúde mental e atenção básica: o vínculo e o diálogo necessários”, que é um anexo da publicação "Saúde mental no SUS: os Centros de Atenção Psicossocial"22;

2) a cartilha do HumanizaSUS intitulada "Equipe de Referência e Apoio Matricial"23.

O documento da Secretaria Municipal de Saúde sobre Interconsulta analisado foi o "Plano de Saúde Mental 2005-2008”24.

Nos documentos do Ministério da Saúde são propostas como tarefas do Apoio Matricial: a discussão de caso, a capacitação, a consulta conjunta, a participação em reunião de equipe na rede básica, a visita domiciliar, a disponibilização de contato telefônico para emergências. O Apoio Matricial tal qual se encontra nestes documentos propõe produzir um novo "arranjo organizacional", que visa fornecer um "suporte técnico" às ações básicas ${ }^{22}$, modificar relações e processos de trabalho tidos como fragmentados e alienados, horizontalizar e democratizar relações. A Cartilha refere que o serviço de saúde que concentra as decisões na alta hierarquia "e cuja organização é baseada no poder das corporações profissionais, tende a gerar descompromisso e falta de interesse de participação na maioria dos trabalhadores." 23 .

E estes documentos se endereçam a um profissional com este perfil tradicional que trabalha de forma fragmentada e não articulada, têm como diretriz que a APS possa aumentar a resolutividade de atendimento aos casos de saúde mental, e, através da responsabilização compartilhada excluir ou superar a lógica de encaminhamento aos serviços especializados.

Os documentos do Ministério da Saúde analisados criam novas formas de produzir sujeitos profissionais na saúde, com novas formas de ver, dizer e julgar - como referiu Larrosa ${ }^{25}$ ao definir o processo de subjetivação - a saúde mental e a saúde. A partir da contribuição foucaultiana, Larrosa $^{25}$ considera que subjetivar-se é aprender a ver-se, dizer-se e julgar-se de uma determinada forma, é a experiência de si mesmo em um dado jogo de verdade. Para este autor, as teorias e as práticas pedagógicas e terapêuticas não são meras mediadoras, que dispõem os recursos para o desenvolvimento do sujeito, mas produzem as pessoas, sendo constituidoras das subjetividades, da relação do sujeito consigo e com os outros. Os profissionais da saúde não são só subje- tivados pela sua formação profissional acadêmica, mas também os documentos e as práticas - como da Interconsulta e do Apoio Matricial produzem o objeto sobre o qual trabalham e também os sujeitos profissionais que os realizam.

Estas novas formas de ver, dizer e julgar expressam-se nas novas nomenclaturas utilizadas nestes documentos. Por exemplo, os dados sobre prevalência em saúde mental na população são apresentados conforme a modalidade de cuidados que esta necessita - "cuidados contínuos (transtornos mentais severos e persistentes)" ou "eventual (transtornos menos graves)" 22 , e não apenas a partir de transtornos psiquiátricos, como comumente são apresentados. O posto de saúde é denominado de "equipe de referência" enfatizando a responsabilidade da equipe da rede básica sobre os casos, e o serviço especializado é denominado de "serviços de referência/especialidades"23, enfatizando também sua responsabilidade enquanto referência secundária.

A Interconsulta, presente no documento da Secretaria Municipal da Saúde de $2005^{24}$, propõe como fazendo parte de suas atividades a discussão de caso e a realização de capacitação, e embora cite autores que apontem como tarefa da Interconsulta abordar questões interpessoais, institucionais e de equipe, o documento não destaca estes aspectos. Ela é dirigida mais para a orientação sobre questões técnicas como o manejo da medicação, do diagnóstico e da conduta técnica. Este documento da SMS é permeado pela noção de "evidências" que considera como secundárias ou desconsidera informações socioculturais e psicológicas, segundo Castiel e Diaz ${ }^{26}$. E, por outro lado, ao mesmo tempo, também é permeado por noções da Reforma Psiquiátrica de inclusão social. A Interconsulta no documento da SMS pretende qualificar os encaminhamentos da APS para os serviços especializados, diferente do Apoio Matricial proposto pelo Ministério da Saúde que, como vimos, parece pretender principalmente aumentar a resolutividade da APS. A Interconsulta parece ter o foco de atuação mais restrito do que o Apoio Matricial que tem uma pretensão de modificar a forma de se organizar o trabalho nas instituições e equipes, além de propor a realização de consultas conjuntas. Apesar das diferenças apontadas, as atividades que são propostas como fazendo parte da Interconsulta estão contidas nas atividades que o Ministério da Saúde propõe como Apoio Matricial em saúde mental.

E tanto a Interconsulta quanto o Apoio Matricial afirmam a saúde mental como tão impor- 
tante quanto a saúde física, propõem novas formas de organização das relações de poder entre os profissionais, de saber e de verdade na saúde, afetando usuários e profissionais. Elas direcionam os sujeitos profissionais da saúde mental para que realizem interdisciplina e ensinem os demais profissionais a praticá-la, assim como a intersetorialidade, e que compartilhem responsabilidade sobre os casos.

Pode-se dizer, então, que os documentos do Ministério da Saúde e da SMS compõem um modo de falar sobre a saúde e de gerenciá-la, que está inserido em valorações e verdades que tanto se referem ao momento atual das políticas públicas brasileiras, quanto a propostas assumidas por documentos e entidades de saúde internacionais e da ciência. Valoriza-se a Atenção Primária à Saúde, a atenção à saúde mental na Atenção Primária, inserindo o doente na comunidade e não segregando em internações hospitalares, a integração entre os serviços da saúde e a intersetorialidade entre a saúde e outras instituições que não da saúde.

\section{Modus operandi, críticas e estratégias do apoio matricial e da interconsulta}

A forma de realizar este trabalho de integração dos profissionais do serviço de saúde mental e dos profissionais da rede básica tem variado na SMS de Porto Alegre e nem todos os serviços de saúde mental as realizam, assim como nem todo posto de saúde participa. Em um dos formatos, os profissionais de diferentes postos da APS reúnem-se quinzenalmente ou mensalmente no serviço de saúde mental junto com os profissionais deste serviço para discutir casos e formular Planos Terapêuticos Singulares conjuntamente. Alguns clínicos gerais e médicos de família entrevistados consideraram bastante produtiva este formato de reunião, referiram aprender também com a troca de experiência com colegas de outros postos da rede básica, assim como com profissionais da saúde mental. Num outro formato, os profissionais dos serviços de saúde mental dirigem-se a cada posto de saúde para realizar esta atividade, geralmente mais de um profissional de áreas diferentes. A denominação empregada pelos profissionais para esta atividade varia bastante, alguns chamam de Consultoria, outros de Interconsulta - termo empregado no documento da SMS de 2005 já citado ${ }^{24}$ - e outros de Apoio Matricial, tal como utiliza o Ministério da Saúde. Os profissionais realizam uma apropriação bastante particular destas noções, sem necessaria- mente seguir as definições oficiais do Ministério da Saúde ou da Secretaria Municipal da Saúde. Em vários serviços este trabalho da saúde mental com a rede básica já acontece há mais de cinco anos, tendo sido referido tanto pelos profissionais de ambos locais que participam destas atividades, ter ocorrido um forte aprendizado no período.

Nem todos profissionais são favoráveis a estas práticas. Um clínico geral se posicionou contra e defendeu o encaminhamento direto de casos aos serviços de saúde mental via documento de referência e contrarreferência por considerar mais rápido do que esperar a reunião para discutir o caso - posição que na minha experiência verifico ser bastante comum entre profissionais das Unidades de Saúde. Esse profissional defendeu que a renovação de receita psiquiátrica, bem como a atenção aos casos deve ser feita pelo especialista, não por um médico clínico geral. Ele diz:

[...] porque às vezes tu fica com um paciente de psiquiatria copiando receita, o clínico fica copiador de receita $[. .$.$] porque a gente não vê o dia a dia$ [do paciente], não conversa, não temos tempo pra saber como é que é a vida dele, né.

Diz ainda que o psiquiatra é quem tem uma visão

[...] mais subjetiva. Vai ter que conversar, perder tempo, por isso que a consulta do psiquiatra é demorada, né?

E completa:

[...] o clínico na verdade, ele deixa de fazer a parte clínica dele que é ver como está o fígado, como é que tá o rim, se tem alguma infecção. $\mathrm{Na}$ verdade tu fica só passando a receita do medicamento que tu não pode retirar também.

Ele costuma renovar as receitas psiquiátricas e participar da Interconsulta nos serviços de saúde mental, porém critica isso, não considera ser sua função abordar os aspectos subjetivos do paciente, mas sim cuidar dos aspectos objetivos como os órgãos, as enfermidades e os exames. Ele se considera um "copiador de receita" psiquiátrica dos usuários que já se trataram em serviços de saúde mental e ganharam alta, ou que aguardam vaga para serem atendidos nestes serviços, pois não se sente preparado para alterar a medicação. Este profissional e tantos outros trabalhadores da SMS demonstram uma forte subjetivação no modelo biomédico que reforça o trabalho dentro das fronteiras das especialidades, voltado para aspectos objetivos e não podendo abordar os aspectos subjetivos do atendimento. Já outro médico, um clínico comunitário, considera que a consultoria de saúde mental ajuda a 
dar um suporte e fazer com que a gente se sinta mais seguro pra atender casos que a gente imagina que não é capaz ou que não é possível atender [...].

Segundo relato de profissionais de serviços de saúde mental entrevistados, é comum os profissionais da rede básica alegarem não terem tempo para atender a saúde mental, ou não se sentirem preparados ou capacitados para tal, e não reconhecerem a renovação de receita psiquiátrica como uma atenção que já realizam na área de saúde mental. Sendo a estratégia inicial de alguns profissionais da saúde mental entrevistados, auxiliar para que os médicos da rede básica reconheçam que a renovação de receita psiquiátrica já é uma assistência em saúde mental e que é possível qualificá-la.

Outra estratégia utilizada na reunião de Interconsulta é a negociação a respeito do usuário a ser acolhido no serviço de saúde mental, que é, segundo um entrevistado, bastante tensionada, pois o número de vagas no serviço de saúde mental é sempre menor do que os pedidos de encaminhamentos pela rede básica. A prioridade é para os casos mais graves, mas, segundo profissionais da saúde mental, algumas vezes admitese um caso menos grave no serviço de saúde mental quando os profissionais da rede básica não estão conseguindo lidar com a situação, apesar do caso já ter sido discutido na Interconsulta, levando em conta os limites e as possibilidades de atendimento dos profissionais da rede básica.

Uma enfermeira de um serviço de saúde mental relatou:

Tem unidades que o paciente grave fica um pouco perdido no cotidiano do trabalho. Então um pouco o nosso papel é puxar esse paciente [...], vamos trazer pro serviço de saúde mental, ver se ele consegue vir, vamos fazer visita domiciliar. [...] A gente ajuda a montar o paciente, digamos.

$\mathrm{Na}$ Interconsulta com a rede básica ela auxilia a "puxar" o caso grave de saúde mental que às vezes fica perdido no cotidiano do trabalho do posto de saúde, a pensar estratégias para trazêlo ao serviço, como a visita domiciliar, por exemplo, e também a pensar junto com a equipe da rede básica que profissionais podem fazer este trabalho. Faz lembrar o que Ana Cristina Figueiredo $^{27}$ chama de "construção do caso clínico", ou seja, a construção coletiva do caso reunindo a contribuição dos profissionais da equipe que o conhecem, a partir do que se colhe das produções do sujeito, e que servirá de indicação da direção de seu tratamento.

\section{O que profissionais referem aprender ou ensinar na interconsulta e no apoio matricial?}

É utilizada no presente trabalho uma leitura ampliada do pedagógico que considera que os processos de aprendizagem não ocorrem somente nos espaços da escola ou das instituições de ensino ${ }^{28}$. Segundo estes autores as aprendizagens ocorrem também em instâncias ou manifestações extraescolares como a mídia, o cinema, a cultura popular, os livros de ficção, as organizações religiosas, assim como acontece também nos documentos e práticas na saúde pública.

Sobre os aprendizados em relação à infância, uma psicóloga referiu que os pediatras da rede básica após a Interconsulta passaram a dar "atenção à história da criança”, escutar também a criança e não só o adulto (as queixas maternas e da escola), a não centrar só no sintoma ou na doença, mas a conhecer o contexto da criança, sua família, e a avaliar mais detidamente os pedidos de encaminhamentos feitos pela escola, modificando muitas vezes o encaminhamento. Por exemplo, um pedido de encaminhamento de uma criança ao neurologista, feito pela escola, pôde ser melhor analisado pelo pediatra do posto de saúde, juntamente com o trabalho da Interconsulta, derivando para um encaminhamento a outro profissional, que se julgou mais adequado para a situação, um psicólogo. A psicóloga diz que esses médicos lhe dizem:

puxa, como foi bom isso [a Interconsulta], como eu aprendi a ter uma escuta maior, né, mais focada no desenvolvimento todo da criança.

Em relação aos adultos, os profissionais da rede básica referiram passar a escutar e conhecer mais a pessoa, obter mais dados sobre sua situação e contexto, a ter mais disponibilidade pessoal e de tempo, a acolher seu sofrimento, a acompanhar longitudinalmente os casos, a motivar o paciente antes de encaminhar ao serviço especializado, a não se assustar com casos de saúde mental e enxergá-los de outra forma (não como o "chato", o insistente ou o incompreensível), sentindo-se mais capacitados para atendê-los e entendê-los, aprenderam a dar uma "atenção integral" e atentar para a "dor na alma", conforme relatos. A partir da "Consultoria” uma clínica geral diz ter passado a atender os casos menos graves dando "apoio" e "atenção", e a só encaminhar ao serviço de saúde mental os mais graves, ela diz: Quanta gente senta na nossa frente e começa a chorar. Eles não vêm com o problema de estar com uma dor. A dor deles é dor na alma. 
Pode-se dizer que os profissionais referiram ter havido uma certa complexificação da visão dos casos e ampliação das próprias práticas pois passaram a escutar mais, realizar acompanhamento sistemático de alguns casos, e alguns até a realizar grupos e/ou oficinas. Um entrevistado de um serviço de saúde mental enfatizou que este trabalho ajuda a rede básica a planejar e organizar a assistência com o usuário que necessita de cuidados na área de saúde mental.

Referiram que passaram a valorizar a troca interdisciplinar e também aquela entre profissionais da mesma profissão como processo de aprendizagem, a "parar para conversar" sobre o trabalho e sobre os casos, algo que muitas vezes não acontece no cotidiano atribulado da rede básica que recebe demandas muito variadas em saúde. Além disso, em algumas situações passaram a chamar outros serviços que não são da saúde, como por exemplo, o Conselho Tutelar e a escola, para discutir intersetorialmente alguns casos.

Assim, pode-se dizer que nestas práticas de Interconsulta e Apoio Matricial os sujeitos profissionais são subjetivados e se autoproduzem para modificarem suas práticas e realizarem aproximação entre serviços e entre diferentes profissões, trabalhar de forma coletiva em equipe, dividindo responsabilidades e se comprometendo. E o sujeito paciente é incentivado a se inserir socialmente e não ser segregado, se torna um caso construído e discutido procurando levar em conta seu contexto e singularidade. São práticas que tornam mais resolutiva a atenção em saúde mental e no SUS, que não substituem os serviços especializados, mas se somam a eles.

Porém, os profissionais também relataram as seguintes dificuldades: nem sempre acontece trabalho em equipe ou interdisciplina dentro da rede básica e/ou desta com o serviço especializado; nem todos os serviços de saúde mental realizam ou da rede básica participam da Interconsulta ou da atividade de Apoio Matricial; o atendimento dos casos de saúde mental e a participação na Interconsulta e no Matriciamento são centrados ainda no profissional médico, alguns profissionais da saúde mental tentam incluir também a contribuição dos outros profissionais da rede básica na discussão dos casos; os médicos relatam que comumente não incluíam a saúde mental nas suas ações antes da Interconsulta ou do Matriciamento.

\section{Práticas discursivas e subjetivações contemporâneas}

O discurso encontrado nos documentos do Ministério da Saúde sobre o Apoio Matricial e também nas entrevistas analisadas, que enfatiza a interdisciplinaridade, a responsabilidade compartilhada, assim como a valorização igualitária de todos os saberes disciplinares, a não hierarquização de serviços nem de saberes, e a democratização das relações de trabalho, parece fazer parte de outro social mais amplo, contemporâneo.

Este discurso presente na saúde contra o modelo piramidal biomédico - que é a expressão do modelo patriarcal na saúde, segundo Capra $^{12}$, e em prol das relações horizontais, da democracia e da transdisciplinaridade, parece relacionar-se muito ao que Lebrun ${ }^{29}$ chama de organização social contemporânea. Lebrun ${ }^{29}$ destaca em relação ao passado mudanças na forma de convívio e na organização do laço social: antes na sociedade predominava a verticalidade, a autoridade dada pela tradição, o modelo de organização social piramidal, a ordem preestabelecida transmitia as regras. A legitimidade social era dada pela teologia e pela supremacia masculina do patriarcado, o religioso era o modelo do social. Segundo Lebrun ${ }^{30}$, antes a autoridade era ocupada por Deus, pelo Papa, pelo pai ou pelo chefe, e hoje a organização social não está mais constituída como pirâmide, mas como rede e este lugar de autoridade não tem mais o reconhecimento espontâneo de antes, o modelo anterior foi paulatinamente enfraquecido pelo discurso da ciência e pelos avanços da democracia. Na modernidade $^{29}$ há mudança na maneira de decidir, passou-se a defender a contratualidade, a horizontalidade e a paridade democrática, a pluralidade passou a ser reconhecida com suas convergências e divergências. Hoje considera-se que a decisão deve vir da confrontação e da discussão entre os protagonistas, da troca entre interlocutores, a ordem deve emergir do convívio entre os parceiros, ela não está dada de antemão, espera-se dos atores que estejam implicados e que não sejam apenas submetidos. Lebrun ${ }^{29}$ refere que a autoridade hoje se sustenta nessa organização mais horizontal e negociada, e aceita a interpelação. Essas questões da corresponsabilização dos profissionais da rede básica com as situações de saúde mental, e não só do encaminhamento des- 
comprometido, bem como das decisões sobre o trabalho que se constroem coletivamente e não apenas se impõem verticalmente, aparecem muito nos discursos e nas práticas analisadas por esta pesquisa, especialmente nos documentos do Ministério da Saúde citados e nas entrevistas, corroborando a ideia de mudança de alguns discursos e práticas da saúde tal como vem acontecendo no discurso social contemporâneo.

\section{Referências}

1. Silveira ER. Práticas pedagógicas na saúde: o apoio matricial e a interconsulta integrando a saúde mental à saúde pública [tese]. Porto Alegre (RS): Universidade Federal do Rio Grande do Sul; 2011.

2. Hall S. The work of representation. In: Hall S, organizador. Representation: cultural represantations and signifying practices. London: Thousand Oaks; 1997. p. 11-73.

3. Ceccim R. Equipe de saúde: a perspectiva entredisciplinar na produção dos atos terapêuticos. In: Pinheiro R, Mattos R, organizadores. Cuidado. As fronteiras da integralidade. Rio de Janeiro: IMS/ UERJ, CEPESC, Abrasco; 2005. p. 259-278

4. Organização Mundial da Saúde (OMS). Relatório sobre a saúde no mundo 2001. Saúde mental: nova concepção, nova esperança. Genebra (Suíça): OMS; 2001.

5. World Health Organization (WHO), World Organization of Family Doctors (WONCA). Integrating mental health into primary care. A global perspective. [site na Internet]. Geneva: WHO; 2008. [acessado 2010 mar 20]. Disponível em: http://www. who.int/mental_health/policy/Integratingmhinto primarycare2008_lastversion.pdf

6. Declaração de Caracas. Conferência Regional para a Reestruturação da Assistência Psiquiátrica dentro dos Sistemas Locais de Saúde [site na Internet]. Caracas (Venezuela): 1990. [acessado 2008 set 9]. Disponível em: http://portal.saude.gov.br/portal/ saude/cidadao/visualizar_texto.cfm? idtxt $=23107$

7. Brasil. Ministério da Saúde (MS). Secretaria de Atenção à Saúde. Departamento de Atenção Básica. Diretrizes do NASF. Núcleo de Apoio à Saúde da Família. Brasília: MS; 2009.

8. Lancetti A, Amarante P. Saúde mental e saúde coletiva. In: Campos GW, organizador. Tratado de saúde coletiva. São Paulo: Hucitec; 2006. p. 615-634.

9. Foucault M. Microfísica do Poder. 11 a Edição. Rio de Janeiro: Graal; 1993.

10. Kendall G, Wickham G. Parte I, A história, arquelogia, genealogia e o discurso como pedras angulares dos métodos de Foucaul. In: Kendall G, Wickham G, organizadores. Usando os métodos de Foucault. London, Thousand Oaks, Delhi: Sage; 1999. p. 4-21.
11. Luz MT. Natural, racional, social. Razão médica e racionalidade científica moderna. Rio de Janeiro: Campus; 1988.

12. Capra F. O ponto de mutação. A ciência, a sociedade e a cultura emergente. São Paulo: Cultrix; 1982.

13. Minayo MCS. O desafio do conhecimento: pesquisa qualitativa em saúde. 11 a Edição. São Paulo: Hucitec; 2008.

14. Ceccim R, Capazolo A. Educação dos profissionais de saúde e a afirmação da vida: a prática clínica como resistência e criação. In: Marins J, Rego S, Lampert JB, Araújo JGC, organizadores. Educação médica em transformação: instrumentos para a construção de novas realidades. São Paulo: Hucitec; 2004. p. 346-390.

15. Organização Mundial da Saúde (OMS). Constituição da Organização Mundial da Saúde (OMS/WHO) [site na Internet]. Genebra: OMS; 1948. [acessado 2007 dez 7]. Disponível em: <http://www.fd.uc.pt/ CI/CEE/OI/OMS/OMS.htm>.

16. Brasil. Constituição da República Federativa do Brasil de 5 de outubro de 1988. Diário Oficial da União 1988; 5 out.

17. Brasil. Ministério da Saúde. Secretaria de Atenção à Saúde. DAPE Reforma psiquiátrica e política de saúde mental no Brasil. Documento apresentado à Conferência Regional de Reforma dos Serviços de Saúde Mental: 15 anos depois de Caracas. Brasília: OPAS; 2005.

18. Declaração de Alma-Ata. Saúde para todos no ano 2000. Conferência Internacional sobre Cuidados de Saúde Primários [site na Internet]. Alma-Ata, Casaquistão (URSS); 1978. [acessado 2008 set 9] Disponível em: http://www.saudepublica.web.pt/05PromocaoSaude/Dec_Alma-Ata.htm

19. Campos G, Domitti A. Apoio matricial e equipe de referência: uma metodologia ara gestão do trabalho interdisciplinar em saúde. Cad Saude Publica 2007; 23(2):399-407.

20. Botega NJ. Prática psiquiátrica no hospital geral: interconsulta e emergência. 2a Edição. Porto Alegre: Artmed; 2006.

21. Rose G. Análise do discurso II. In: Rose G, editor. Metodologias visuais - uma introdução a interpretação de materiais visuais. Londres: Sage; 2001. p. 163-186. 
22. Brasil. Ministério da Saúde (MS). Secretaria de Atenção à Saúde. Departamento de Ações Programáticas Estratégicas. Saúde mental no SUS: os centros de atenção psicossocial. Brasília: MS; 2004.

23. Brasil. Ministério da Saúde (MS). Secretaria-Executiva. Núcleo Técnico da Política Nacional de Humanização. HumanizaSUS: equipe de referência e apoio matricial. Brasília: MS; 2004.

24. Porto Alegre. Prefeitura Municipal de Porto Alegre. Secretaria Municipal de Saúde. Plano de saúde mental 2005-2008. Porto Alegre: Secretaria Municipal da Saúde; 2005.

25. Larrosa J. Tecnologias do eu e educação. In: Silva TT, organizador. O sujeito da educação. Estudos Foucaultianos. 5a Edição. Petrópolis: Vozes; 2002. p. 35-97.

26. Castiel LD, Diaz CAD. A saúde persecutória. Os limites da responsabilidade. Rio de Janeiro: Fiocruz; 2007.

27. Figueiredo AC. A construção do caso clínico: uma contribuição da psicanálise à psicopatologia e à saúde mental. Rev Latin Psic Fund 2004; 7(1):75-86.

28. Wortmann ML. Análises culturais - um modo de lidar com histórias que interessam à educação. In: Costa $\mathrm{M}$, organizadora. Caminhos investigativos II: outros modos de pensar e fazer pesquisa em educação. Rio de janeiro: DP\&A; 2002. p. 73-92.

29. Lebrun JP. Clínica da instituição. O que a psicanálise contribui para a vida coletiva. Trad. Sandra Chapadeiro. Porto Alegre: CMC Editora; 2009.

30. Lebrun JP. Ensinem os filhos a falhar. Veja 2009; 42(49): 21-25.

Apresentado em 12/05/2011

Aprovado em 11/07/2011

Versão final apresentada em 10/09/2011 